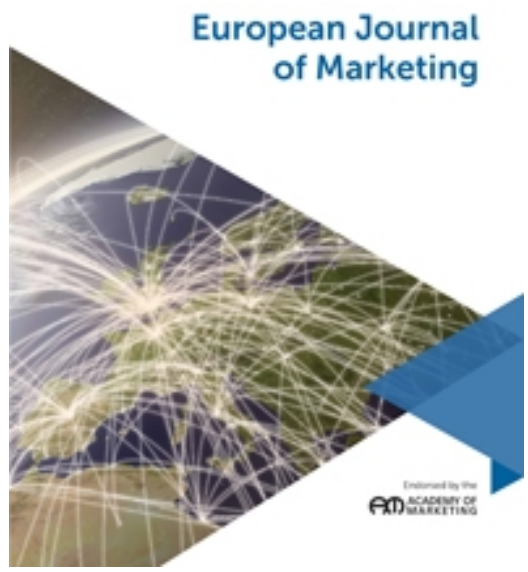

\title{
Introducing the socialbot: A novel touch point along the young adult customer journey
}

\begin{tabular}{|r|l|}
\hline Journal: & European Journal of Marketing \\
\hline Manuscript ID & EJM-07-2019-0555.R2 \\
\hline Manuscript Type: & Original Article \\
\hline Keywords: & $\begin{array}{l}\text { Socialbots, Customer Journey, Customer Experience, Touch Point, Social } \\
\text { Networking Sites, Artificial Intelligence }\end{array}$ \\
\hline \multicolumn{2}{|l}{} \\
\hline
\end{tabular}

\section{SCHOLARONE ${ }^{\mathrm{m}}$ Manuscripts}

Publisher policy allows this work to be made available in this repository. Published in European Journal of Marketing by Emerald. The original publication is available att: https://doi.org/10.1108/ejm-07-2019-0555. This article is deposited under the Creative Commons Attribution Noncommercial لnternational icence 4.0(CCBY-NC 4.0). Any reuse is allowed in accordance with the terms outlined by the licence (https:// creativecommons.org/licenses/by-nc/4.0/) To reuse the AAM for commercial purposes, permission should be sought by contacting permissions@emeraldinsight.com. 


\title{
Introducing the socialbot: A novel touchpoint along the young adult customer journey
}

\begin{abstract}
Purpose - This paper contributes to the special issue theme by exploring customer response to automated relationship management tactics on social media channels.

Design/methodology/approach - 17 in-depth interviews of young adults ranging from the age of 19 to 26, were conducted. From this, customer journey maps were compiled incorporating socialbots as a valuable touchpoint along the service delivery cycle.

Findings - The research frames the socialbot as a valued customer service agent to young adults with some favouring this over telephone and email communication methods. Younger consumers respond positively to the quick resolution offered by the socialbot mechanism with most acknowledging the bot is only able to manage simplified requests. Human-tohuman customer relationship management is preferential when the query reaches critical mass.
\end{abstract}

Research limitations/implications - Socialbots on Facebook messenger provided the research context for this study therefore other platforms and owned website bots should be considered in future studies.

Practical implications - This research identifies the younger generation as a key target market for the development of customer service related bots.

Originality/value - This work is the first to examine the socialbot as an automated touchpoint in the customer journey and contributes knowledge to the growing body of literature focused on $\mathrm{Al}$ in customer service. Moreover, it provides valuable qualitative insights into how socialbots influence the customer experience and related outcome measures.

Keywords - Socialbots, Customer Journey, Customer Experience, Touchpoint, Social Networking Sites, Artificial Intelligence

Paper type - Research paper 


\section{Introduction}

In a world where instant communication through Social Networking Sites (SNS) such as Twitter, Facebook and Instagram is heavily embedded within young adults' lives (Ellison et al., 2008; Utz, 2016), there is an increasing demand for firms to produce instantaneous information (Brandtzaeg and Folstad, 2017). Artificial Intelligence (Al) advancements provide an opportunity for firms to meet the ever demanding consumer needs. Recent advancements in Al and the development of Natural Language Processing (NLP; Kietzmann et al., 2018) has allowed Al systems to analyse human language by deriving meaning from conversations. The goal being to make the interaction between computers and humans feel exactly like humanto-human interaction (Jackins, 2016; Kietzmann et al., 2018). These advances have led to the development of intelligent personal assistants, such as Amazon's Alexa (Han and Yang, 2018; Xu et al., 2017), chatbots, socialbots and intelligent agents. A socialbot, the topic of this paper, is a type of chatbot that simulates human behaviour in automated interactions on SNS (Rouse, 2013).

In 2016, Facebook launched a bot within their Messenger application, known as a socialbot, which permits brands to build a socialbot and communicate with Facebook Messenger users. With over a billion people per month using Facebook Messenger and over 100,000 bots within the application, they are changing the way consumers and brands interact (Sprout Social, 2018). Initially, the socialbot's main purpose was to answer complaints in the customer service departments of businesses (Xu et al., 2017). Due to their success in dealing with complaints, businesses have found other ways to utilise them, which in-turn increases productivity and maximises entertainment (Brandtzaeg and Folstad, 2017). There are consequently a number of motivations for using a socialbot, for example customer service, entertainment, curiosity, productivity and socialising (Brandtzaeg and Folstad, 2017; Kaczorowska-Spychalska, 2018; Xu et al., 2017; Zarouali et al., 2018). However, as an entirely new entity within SNS and a novel form of customer service, there is little understanding of how socialbots impact the customer experience.

Current knowledge demonstrates that socialbots create value for firms, as many adopt the technology to increase cost effectiveness and profits. For example, if businesses were able to use socialbots instead of employing a human based customer service agent, they would be able to reduce costs by $30 \%$ (Reddy, 2017). As a result, it is expected that the socialbot industry will be worth $\$ 1.25$ billion by 2025 (Grand View Research, 2019). There are further benefits to using $\mathrm{Al}$ as it enables brands, retailers and companies to simultaneously process data and use information about individual customers (Daskou and Mangina, 2003), which can enhance segmentation and targeted marketing. Additionally, many brands are starting to use SNS as a sales platform with $40 \%$ of business owners using these channels to generate profits (Arnold, 2018), indicating a suspected shift from e-commerce to social shopping (e.g. purchasing products/services through SNS).

There are few studies relating to how socialbots create value for the consumer, therefore this paper extends the extant scholarship. As SNS are not just a messaging platform, they are an area where meaningful interaction can take place, socialbots may be used to build a strong customer relationship (Hanna et al., 2011; Xu et al., 2017). However, previous research mainly 
identifies the motivations for using socialbots (Branstzaeg and Folstad, 2017) or the technology that powers them, rather than the potential customer relationship. It is suggested that emotional empathy could develop between people and computers when communication is frequent and regular (Han and Yang, 2018) and that customers prefer emotive socially intelligent agents (Neururer et al., 2018) but the understanding of this impact on the consumer is limited. Current concerns with the socialbot phenomenon include privacy, security risks, potential detrimental effects on the consumer and dehumanisation of the customer-business relationship (Ho and Ito, 2019; Han and Yang, 2018; KaczorowskaSpychalska, 2018). The present paper therefore explores these potential concerns by establishing how customers interact with socialbots on SNS and what impact this has on their customer experience.

The current study focuses on young adults as they are the primary segment of consumers engaging with SNS (Ho and Ito, 2019) and socialbots. By generating $30 \%$ of retail sales in the US (Donnelly and Scaff, 2018), this segment holds a significant proportion of purchasing power and considerable influence, which has attracted attention from businesses and academics (Komidar et al., 2014; Moore, 2012; Pate and Adams, 2013; Pozza et al., 2017). Compared to older generations, these consumers rely on and live in a world surrounded by technology (Pate and Adams, 2013). Due to the recent development of socialbots there is minimal knowledge, especially of how young adults engage with this technology (Brandtzaeg and Folstad, 2017; Xu et al., 2017; Zarouali et al., 2018).

Consequently, the aim of this study is to explore the experiences of young adults using socialbots by adopting a customer journey framework from the customer experience literature (Lemon and Verhoef, 2016). Theoretically, the paper contributes to current understanding of customer experience by highlighting the importance of incorporating an alternative touchpoint, the automated touchpoint (ATP), into the process model for customer journey and experience (Lemon and Verhoef, 2016). This is to account for Al and automated related touchpoints, such as socialbots. Moreover, the qualitative exploration provides insights into how socialbots alter the customer experience and recommendations are made on how this novel touchpoint may be linked to outputs such as customer equity. Practically, the research develops understanding of young adults' customer journeys relating to products and services that utilise socialbots for customer service, promotion and information gathering in order to develop recommendations relating to usage of this technology.

The paper is organised as follows. The subsequent section provides a review of the literature on customer service within the customer experience, omnichannel touchpoints and outputs relating to customer touchpoints. This is succeeded by an explanation of the chosen methodology alongside sampling, research and analysis methods. The findings emerging from the data are then presented. Finally, the theoretical and practical implications of the paper are discussed alongside limitations and directions for future research.

\section{Literature Review}

Customer service within customer experience 
Customer service has been found to be essential in many areas of marketing such as customer satisfaction and loyalty (Bolton, 1998), service quality (Parasuraman, et al., 1988), relationship marketing (Berry, 1995; Sheth and Parvatiyar, 1995), customer relationship management (Ngai, 2005) and customer engagement (Brodie et al., 2011). More recently, customer service features heavily within the customer experience literature and throughout the customer journey (Juttner et al., 2013; Lemon and Verhoef, 2016). The idea of the customer journey was originally born out of the service marketing literature. For instance, service blueprinting was the primary endeavour to map the customer journey and has had influence on key stages of the journey metrics such as critical incidents, otherwise known as moments of truth (Bitner et al., 2008; Shostack, 1987). Moreover, an understanding of the influence of the environment and atmospherics on the customer experience (Bitner, 1990; 1992) has been at the forefront of the customer experience focus on context. Since its inception from service marketing into a customer centric approach, the concept of customer experience has evolved into a multidimensional construct, which focuses on the emotional, behavioural, cognitive, social and sensory customer responses to a company throughout the complete customer journey (Lemon and Verhoef, 2016).

The majority of recent customer experience literature that relates directly to customer services are based within services marketing (Halvorsrud et al., 2016; Lariviere et al., 2017; Tax et al, 2013; Teixeria et al., 2012; Varnali, 2019; Voorhees et al., 2017). As a result, understanding of the impact of customer services seems predominantly embedded within service encounters (Tax et al., 2013; Voorhees et al., 2017), service quality (Halvorsrud et al., 2016) and service design (Teixeria et al., 2012). Within present society, as online shopping continues to increase (Bleier et al., 2019) and Al is unceasingly enhanced (Brandtzaeg and Folstad 2017), it is essential to comprehend customer service, beyond the services literature, and within the context of purchasing a product. As such, by applying principles and tools from the customer experience scholarship, such as the customer journey (Lemon and Verhoef, 2016), the impact of customer services on a consumer can be explored throughout the entire customer experience for firms operating in both service and product-based industries.

As firms are beginning to value each customer as an individual with different experiences, scholarship and practice are exploring ways of transitioning from mass marketing to a tailored approach (Batra and Keller, 2016; Kietzmann et al., 2018; Lemon and Verhoef, 2016). For instance, Al based customer services, such as socialbots are being used so that instant big data can continuously monitor consumer behaviour (Kietzmann et al., 2018), which enables marketers to offer this individualised tactic. Furthermore, the growth of social media provides marketers with infinite communication possibilities to personalise message content, timing and location (Batra and Keller, 2016). This approach is perceived to be an effective business strategy to adopt, as it can lead to customers having a positive experience (Bolton et al., 2018; Puccinelli et al., 2009), which impacts repeat purchases and word-of-mouth recommendations (Daskou and Mangina, 2003). There is, however, scope to further understand the impact of these technological personalised approaches on the consumer, by using the customer experience literature as a theoretical lens. 
The customer journey is a recent development that has emerged from the customer experience body of knowledge, it is therefore theoretically in its infancy and is continuously being altered and improved. For instance, recent debates involve the differences between a customer and a consumer journey (Hamilton and Price, 2019). The prior relating to a strategic focus on customers, whilst the latter acknowledges the consumer as an individual with intricate experiences, multiple journeys and a complex life, intertwined with commercial products and services (Hildebrand and Schlager, 2019; Novak and Hoffman, 2019). Despite the recent advancements in consumer journeys, for this paper the customer journey concept provides a necessary emphasis on understanding the how Al, being used strategically for customer service, influences the customer experience (Lemon and Verhoef, 2016).

Furthermore, a review of literature on customer journeys results in an unclear definition of what a journey is, as the number of stages regularly differs (Batra and Keller, 2016; Kietzmann et al., 2018; Lemon and Verhoef, 2016; Puccinelli et al., 2009). One approach to understanding the customer journey is to divide the journey into pre-purchase, purchase and post-purchase with four categories of customer experience touchpoints in each of the three stages (Lemon and Verhoef, 2016). In contrast, Batra and Keller (2016) believed the process was more complex and used ten stages to understand the journey. They stressed the importance of satisfying customers at each of these points, as each stage comes with a number of risks and the premise of a successful customer journey could fail at any one of these stages. Despite this ideology, Wolny and Charoensuksai (2014), Puccinelli et al. (2009) and Kietzmann et al. (2018) considered ten stages as too complex. Regardless of the conflicting views across literature on the number of stages in the customer journey, such variations are all underpinned by the same ideas. As this study is focussing on a specific touchpoint, the socialbot, and has a customer as opposed to a consumer focus (Hamilton and Price, 2019), we adopt the Lemon and Verhoef (2016) model of the customer journey, which is divided into three stages; pre-purchase, purchase and post-purchase, in order to provide a simplified clarity on the impact that socialbots have on the customer experience.

\section{Omnichannel touchpoints}

In relation to customer experience, the omnichannel literature is the most advanced as it contributes to aspects of the customer journey. For instance, studies have evolved from focussing on one particular channel such as catalogues (Leeflang et al., 2013) to several channels utilised across the phases of the experience (De Keyser et al., 2015). Consequently, recent scholarship identifies two different types of omnichannel shopping; webrooming, which involves searching online but buying in store (Verhoef et al., 2007) and showrooming, which involves browsing in store but purchasing online (Brynjolfsson et al., 2013; Rapp, 2015). With the introduction of new technologies such as smartphones, tablets, Al and virtual reality, the omnichannel experience increases in complexity. For example, using a mobile phone in store can encourage the consumer into showrooming as it is possible to view the product and search for offers online simultaneously (Rapp, 2015). It has been discovered that mobile technologies interact with and can affect existing channels (Lemon and Verhoef, 2016). Now that $\mathrm{Al}$ in the form of chatbots and socialbots are available in online and mobile channels, it 
is important to understand how this automated customer service impacts the customer experience. One way to do this is to investigate socialbots as a touchpoint along the customer journey (Baxendale et al., 2015; De Haan et al., 2016).

Due to the increase of e-commerce and m-commerce, customers now interact with firms at countless touchpoints in multiple channels and media (Lemon and Verhoef, 2016; Wolny and Charoensuksai, 2014). Touchpoints are often characterised into different themes in order to comprehend the complexity. For instance, Stein and Ramaseshan (2016) identified seven themes relating to customer experience touchpoints including; atmospherics, technological, communicative, process, employee-customer interaction, customer-customer interaction and product interaction, whereas Lemon and Verhoef (2016) identified the touchpoints as brand-owned, partner-owned, customer-owned and social/external. The consensus from the literature, however, is the importance of each touchpoint, as each time a consumer connects with an organisation the interaction can result in progress to the next stage of the journey or complete discouragement (Batra and Keller, 2016; Lemon and Verhoef, 2016; Stein and Ramaseshan, 2016; Wolny and Charoensuksai, 2014). It is also important to acknowledge the customer experience as subjective, and personal to the individual, making the customer journey and touchpoints difficult to standardise (Stein and Ramaseshan, 2016). Understanding socialbots on a customer level, as an ATP, is therefore imperative in understanding the value that they add to the customer experience.

Socialbots are relatively new tools used in business; there is the potential for cost-saving benefits but the response by customers is still unknown. One of the current motivations for using a socialbot is curiosity, due to the novelty of the tool (Brandtzaeg and Folstad, 2017). However, once the novelty factor no longer exists, socialbots will be required to meet consumer needs in order to remain useful. Zarouali et al. (2018) evaluate consumers' attitudes towards socialbots, and discover that perceived helpfulness and usefulness are influential. Equivalently, Xu et al. (2017) also found helpfulness to be a significant factor in the evaluation of the socialbot. Evidently, the literature has identified core factors that a socialbot requires to successfully meet consumers' needs but as socialbots were only developed in 2016 (Brandtzaeg and Folstad, 2017), there is limited academic research into the topic, creating a number of potential areas for future study. To date, there is no research evaluating the influence that socialbots could potentially have on the customer experience. Thus, the prominent gap in the existing research provides a primary rationale to investigate the socialbot as a touchpoint along the customer journey.

It is difficult to categorise socialbots as a touchpoint within one of the four categories identified by Lemon and Verhoef (2016). For example, they could be brand-owned and operated by the subject firm; they could also be partner-owned as in this instance, Facebook messenger provide the platform; they could be customer-owned as a customer has a choice of interaction with the firm and the choice to use socialbots on Facebook messenger, finally by being situated on SNS, they could also be subject to social and external touchpoints. As a result, it is not clear where the socialbot fits within the Lemon and Verhoef (2016) customer 
journey and experience process model, as this framework was developed before socialbots and chatbots were common practice. Lemon and Verhoef (2016) admit that when it comes to technology, there are blurred lines between the brand-owned and partner-owned touchpoints, as an update by the partner-owned software or device may pressure the brandowned service or application to be altered. Introducing ATPs within the framework would help account for these blurred circumstances. The authors therefore argue that the socialbot is an ATP, which is an automated and computerised form of interaction integral to omnichannel marketing (Lajante, 2019; Singh and Hess, 2017). Examples include chatbots, socialbots, interactive voice recognition (McCartan-Quinn et al., 2014) and automatic selfservice technologies (Blut et al., 2016; Meuter et al., 2005).

\section{Consequences of customer touchpoints}

The outcomes related to the customer touchpoints, the customer journey and the customer experience is an understudied area of research. For example, the customer journey models generally focus on the purchase as the ultimate outcome of experiencing different touchpoints (Anderl et al., 2016; Li and Kannan, 2014; Xu et al., 2014). Additionally, they identify the interactions between touchpoints and these interactions impact purchase behaviour (Wang et al., 2015). Lemon and Verhoef (2016) consequently call for the customer experience to be better linked to outcome measures, not just relating to conversion, but also to long-term loyalty. As a result, there is scope for touchpoints, such as the socialbot, to be linked with models relating to both the purchase outcome and long-term loyalty.

One way of measuring long-term loyalty is through Customer Lifetime Value (CLV; Gupta et al., 2006; Kumar and Reinartz, 2016), which can result in shareholder value creation (Kumar and Shah, 2009). However, there were disagreements as to the whether strategies involving CLV had enough of a focus on the value being provided to consumers. In response to this, the customer equity framework was developed by Zeithaml et al. (2001); this framework identifies whether investments in quality, brands and customer relationships impact CLV (Rust et al., 2004). Customer equity is traditionally defined as the total of the discounted lifetime value of all the firm's customers (Zeithaml et al., 2001). In other words, the firm's value is dependent on the consumers' perceptions of future purchases with the firm. Therefore, the firm needs to comprehend why the consumer initially invests in the firm and how to influence the consumer to continue to repurchase, time and time again (Zeithaml et al., 2001), which enhances customer loyalty (Ou et al., 2017).

According to the literature there are three areas where the firm can impact the initial consumer purchase and re-purchase; value equity, brand equity and relationship equity (Lemon et al., 2001; Rust et al., 2004). Value equity is the customer's assessment of the utility of the brand and the three key sub-categories within this construct are: quality, price and convenience (Lemon et al., 2001: 22). Value equity can also be enhanced when firms introduce innovative products and services (Lemon et al., 2001). Brand equity is "the customer's subjective and intangible assessment of the brand, above and beyond its objectively perceived value" (Lemon et al., 2001: 22). The key levers within brand equity are brand attitudes, brand awareness and corporate social responsibility. Finally, relationship 
equity is what ties the consumer to the firm; it is defined as the propensity of the customer to stay with the brand, withholding the customer's objective assessment of the brand (Lemon et al., 2001: 22). For example, included within the relationship equity driver are loyalty programs, affinity programs and knowledge-building programs. These drivers have been shown to affect consumer loyalty intentions, which have an impact on future sales (Vogel et al., 2008). The drivers are pertinent to the current study and how socialbots can create customer value, change customer relationships with the firm and encourage loyalty to the brand.

\section{Methodology}

The aim of this study is to develop a deeper understanding of the impact that socialbots, as an ATP, have on young adults' experiences and customer journeys. As there is a lack of research on this novel touchpoint for this segment of consumers (Konus et al., 2008), the present study took an overall inductive approach, where the research process was developed from empirical materials and not from theoretical propositions (Eriksson and Kovalainen, 2016). This was in an attempt to draw conclusions from the data in order to enhance and develop theoretical understanding. Being exploratory in nature, qualitative in-depth interviews (Mariampolski, 2001) were used to establish the relationship that young adults have with socialbots and how this affects other touchpoints and outcomes of their customer experience (Lemon and Vehoef, 2016). Purposive sampling was used as a deliberate selection of participants conforming to pre-determined criteria (Kent, 1999). Participants were therefore selected based on age, location and prior experience of using socialbots on Facebook Messenger.

The majority of current literature on socialbots uses a quantitative approach with much larger sample sizes' (Brandtzaeg and Folstad, 2017; Xu et al., 2017; Zarouali et al., 2018), however, as the aim of the study was not to generalise the findings, but to understand the nature of the phenomenon from knowledgeable informants. Purposive sampling was thus deemed an effective approach to find appropriate participants (Krishnaswami and Satyaprasad, 2010). For the purpose of this research, young adults were defined as between the ages of 18 and 29. Participants were invited to take part in the research from promotional recruitment information posted on a Facebook community page of students and alumni for a UK University. Recruitment information contained a screening question, similar to that used by Brandtzaeg and Folstad's (2017) study to ensure participants met the age and experience characteristics. The sample consisted of 17 people with varying levels of socialbot experience; ranging from frequent, daily users to infrequent users who have only had a few experiences (Table 1). In total, there were 5 daily, 5 weekly and 7 monthly users. The participants varied in gender, with 9 females and 8 males. All were between the ages of 19 to 26 .

In total there were 17 in-depth semi-structured interviews conducted, lasting between 40 and 90 minutes. These were all carried out by the same researcher between December 2018 and March 2019 in a central location of Scotland. In-depth interviews were used as they provided opportunity for participants to share their personal experiences without being disturbed or influenced by others (Rubin and Rubin, 2005), which is imperative when collecting information on the customer journey. The interview consisted of semi-structured open-ended 
questions so that the interviewer was not constrained by a pre-determined structure and could probe for more details when necessary (Kent, 1999; Krishnaswami and Satyaprasad, 2010). The open-ended nature of the interview meant that the process of questioning was flexible and responsive to what individuals said. This maximised the opportunities for the researcher to gain insight into the respondents' experiences, feelings, attitudes and ideas (Kent 1999). The participants were asked to recall times when they had used Facebook Messenger socialbots; key questions were prepared in advance to cover the critical points of the customer journey but allowed the interviewees the freedom to express their own views (O'Gorman and MacIntosh, 2014).

The aim was to continue the process until data saturation was achieved (Glaser and Strauss, 1967). Due to the homogeneous nature of the sample and specific topic, only 17 semistructured interviews were required to reach saturation. The data collected from the interviews was recorded and manually transcribed. To further ensure participants privacy, pseudonyms were used throughout the study (O'Gorman and Maclntosh, 2014). The researchers used a thematic analysis to identify emerging themes within the data (Braun and Clark, 2006). One researcher initially coded all the transcripts, following the Braun and Clark (2006) suggested phases of thematic analysis. They firstly familiarized themselves with the data by conducting the transcription of all interviews and then generated initial codes following with an inductive semantic analysis, for instance "less to do with fun stuff or leisure stuff and more to do with if I had a problem or an issue" was coded as "problem solving motivation". The third, fourth and fifth phases; searching for themes, reviewing themes and defining/naming themes, were conducted by all three researchers, until a coding guide was produced. This approach allowed a systematic yet flexible way to analyse the qualitative data whilst sharing initial codes and themes between researchers. During the process, the second and third researchers used the coding guide to validate and check the initial coding and reached an agreement of $95.8 \%$. The themes were used to develop three different customer journeys with varying motivations, emotions, thoughts and touchpoints.

[INSERT TABLE 1]

\section{Findings}

Three customer journeys are identified from the data. The first of which is optimised complaint management referring to young adults using socialbots as a customer service when there is an issue or problem with their purchased product or service. In this instance, socialbots are primarily expected to effectively and efficiently respond the customer, generally during the post-purchase phase. The second journey involves company controlled information sharing experiences, which refer to customers using socialbots pre-purchase to gather information about products or services. The socialbot is programmed to ask the customers questions and provide recommendations based on their answers, hence creating alternative outcomes. The final journey is personalisation through data mining, which is where customer data is utilised to personalise the socialbot's promotion of products and services. The following sub-sections discuss these different customer journeys and the related themes identified from the data. 


\section{[INSERT TABLE 2]}

\section{Optimised complaint management}

The findings indicate that the most frequent customer experience involving socialbots as a touchpoint is the optimised complaint management experience, which is a problem-solving based journey where the socialbot is adopted as a customer service within the post-purchase phase. If the participant has an issue, problem or query relating to their purchased product or service, they interact with the socialbot through Facebook messenger. The socialbot, seemingly has been programmed to reply to customer queries efficiently and effectively. This section identifies the optimised complaint management customer experience relating to a product or service (see Figure 1). Participants disclose that they use socialbots as a form of customer service for quick replies, convenient usage and due to a dislike of other touchpoints, which increases the likelihood of contacting the firm and rectifying negative experiences, hence improving the customer relationship and customer loyalty.

\section{[INSERT FIGURE 1]}

The first theme identified within optimised complaint management is the satisfaction that participants feel from receiving efficient replies from socialbots. Both Laura and Nicola (see Table 2) express the value of quick replies, which lead to successful interaction with the firm and an increased likelihood of usage:

Laura: It definitely helps. I don't think I've had an unsuccessful interaction with the company over messenger [socialbot] because they always are super quick in responding and it's easy to get responses back from them.

Furthermore, the second theme emerging from the data and relating to optimised complaint management is the convenience of using a socialbot. As young adults crave an instant reply when interacting with businesses, the advancements in Al allow socialbots to provide this possibility, especially being present on SNS, where young adult consumers are predominantly based. Jack and Tessa (see Table 2) both discuss the normalcy of continuously being on social media and digital devices:

Jack: I think it's [socialbots are] quite a good idea considering how much people use computers or phones or that kind of thing, especially when you're on a big waiting line. It's easier to type out a message to someone and they are quite good at replying quite quickly.

Consequently, by using socialbots as a customer service, firms are embedding their brand and communications within the everyday lives and journeys of young adults. As such, the data indicates the value that participants place on having quick and convenient interaction with firms. Interestingly these themes also impact other themes within the optimised complaint management experience, such as how socialbots interact with other touchpoints and the changing relationship that customers now have with brands.

For instance, the third identified theme within optimised complaint management is how socialbots interact with other touchpoints along the problem-solving journey. The quick 
replies from socialbots increase the preference of using this touchpoint over other customer service based touchpoints. For example, Rachel demonstrates how socialbots are much more efficient than email:

Rachel: They were fast replying, it was a lot easier than back and forth email because it was more like an open line chat.

Furthermore, if the only options for contacting a business are phoning or emailing it can deter customers from contacting the business. There are several explanations for this including discomfort in the interaction, long waiting times and lack of clarity. Tessa (see Table 2) expresses her dislike of emails whilst Alex exclaims his dislike of phoning companies such as Amazon:

Alex: I just hate it. It sounds so bad but when you call companies there's always chat in the background and they speak really quickly. Like I called Amazon, actually, and it was a nightmare I couldn't understand the guy, he couldn't understand me and then it just didn't work and I had to call him like three times and nothing panned out.

This subsequently emphasises how beneficial socialbots can be to young adult consumers, due to the elimination of long waiting times. Moreover, Laura reports that speaking to a robot is a positive experience, as it minimises any potential discomfort in the interaction with a human:

Laura: It's so much better talking to the bot you don't have to listen to someone and you can convince yourself that it's not a real person and you're fine.

Communication with a bot can have positive implications, as the fears of negative judgments from human-to-human interaction may restrain people in their communication (Ho et al., 2018). Consequently, previous negative experiences of other touchpoints lead to an increased usage of the socialbot as a customer service.

Contrastingly, other participants demonstrate an uncertainty of speaking to robots and a need for human interaction, especially if the issue is one of complexity. Frank and Kathryn (see Table 2) prefer human interaction for issues that they believe to be too complex for a socialbot:

Frank: I think it [the socialbot] would be more for information based stuff. Not for returns; not for returning stuff, not for complaints about a product because I think that needs more of a human element to it. Whereas, the informational side of it, I think that chatbots, at least in my experience with it, they do it really well.

The participants do, however, still acknowledge the value of a socialbot when requiring a quick response. This finding supports the continual use of human-led customer services but also indicates that providing the customer with a choice of channels through which to interact, may create the most value. In other words, the socialbot as a touchpoint is of greatest importance to the consumer when email and phone calls are also available.

A further finding and the fourth theme of the optimised complaint management experience is how the use of socialbots by firms can change and improve the relationship that they have 
with their customers. For example, Rachel articulates that "before I [she] would never phone and ask questions, but I [she] would definitely be more likely to ask questions now that they [socialbots] are there." This offers the firm an opportunity to rectify problems that consumers have with products or services. Molly mentions how socialbots increase the likelihood of her contacting the firm:

Molly: I would say I'm probably more likely to make complaints and things if socialbots are available just purely because I don't like speaking on the phone. I know a lot of other people are like that, so it probably does encourage more people to get help with products or complain about that.

The young adult consumers, through socialbots, develop the confidence to make complaints about a product or service, which could otherwise be a situation in which they may feel judged (Ho et al., 2018). For instance, optimised complaint management (Figure 1) identifies a postpurchase issue with the delivery of a product. The socialbot was able to fix the problem, resulting in a shift in the consumer's opinion of the business. Moreover, having a friendly interaction when dealing with a complaint helps rectify the negative experience. In this example and Angela's experiences (see Table 2), the end feeling the consumer has towards the business is a positive one, as the socialbot is able to solve the problem. Socialbots therefore provide businesses an opportunity to resolve any issues and satisfy the customer post-purchase.

The final theme is how the innovative nature of the technology and how well it is programmed can impact perceptions of the brand and consequently, change the relationship that the consumer has with the brand. Nicola and Alex (see table 2) both explain how they value the innovation that socialbots provide:

Nicola: I think I would like the business more as well because I would feel like they have put a bit more effort into their customer services if they had a personalised conversation [from the socialbot].

The optimised complaint management experience (Figure 1) indicates that even when young adults prefer human-to-human customer services or find socialbots a bit basic, they still admire the innovative nature of the firm to include the technology. In summation, socialbots offer an efficient customer service for customers to solve any issues, and thereby businesses are given the opportunity to rectify any negative emotions that the customer has developed. Bringing a customer service platform to SNS offers convenience and innovation to the customer, as firms are changing relationships and making it easier for customers to make contact.

\section{Company controlled information sharing}

Company controlled information sharing is the second most frequent journey identified from the data. This journey involves the pre-purchase acquisition of information about a product or service, whilst using the socialbot as a touchpoint (see Figure 2). The user's choices and responses lead to suggestions made by the socialbot, which can result in a multitude of different outcomes. For example, Angela recalls engaging with Spotify's socialbot and 
answering questions about her music taste, which results in the bot recommending specific playlists and albums. Kathryn also experiences this with Dr Oetker, where the socialbot asks her pizza preferences and gives a recommendation on what pizza she should purchase: "It recommends what pizza to buy and presents it in this animated video." Finally, Frank shares his experiences of looking for vitamins and the bot asking him tailored questions leading to a specific recommendation:

Frank: It was a vitamin product. So I was looking firstly on the pure gym deals website and then I came across this vitamin thing and then I went in and what popped out was actually really interesting. There was this chatbot thing. If it wasn't for the chatbot I probably wouldn't have even gone through the whole process of looking at things [the vitamins] but because it was a chatbot I actually tried the whole thing [question and answer process] and went through the whole thing and actually at the end, it actually recommended what vitamins I should take and what lifestyle changes I should do.

In this situation, the socialbot enables the firm to take control of the information searching phase of a customer journey. The consumer chooses to engage with the socialbot to gather information about the product or service due to the availability, ease and instant communication provided, however, this process also means that the firm can purposely choose which information to provide the consumer. This creates the illusion that the user has free will but realistically the brand-owned socialbot has an agenda as to which decision the consumer makes.

\section{[INSERT FIGURE 2]}

The first theme identified within company controlled information sharing is the ease of information gathering during the exchange, which provides young adults with an enhanced customer experience. For instance, Angela identifies how having communication prepurchase, provides her with instant information resulting in a smooth transition into the purchasing stage, whilst being fully informed on what to buy:

Angela: I think it would probably encourage me [to shop with the brand] just because I know I can have instant access of information and have the instant gratification type of thing.

Whilst Frank (see Table 2), also mentions how the information a socialbot delivers prepurchase can help him find a product that meets his needs. By creating contact in the prepurchase, information searching phase of a customer journey, firms are able to recommend and provide products and services that are tailored to the individual.

The second theme within company controlled information sharing is how the socialbot acts as a consistent touchpoint throughout the customer experience, enhancing the purchase likelihood. For instance, in Figure 2 the socialbot is initially interacted with for pleasure but then it asks questions and recommends products or services to the consumer; the consumer then has a positive experience and uses the socialbot for future recommendations from the brand. Bill demonstrates the value in being guided through the entire customer journey by a socialbot: 
Bill: For the customer [the socialbot is] a very important part because otherwise there's, there's such a discrepancy between the customer and the company and you don't have any point of contact, except for when you pay in and when you get the product. But if you have the possibility [of using a socialbot], then it's like a guide throughout the whole purchase process.

Furthermore, Rory (see Table 2) highlights the value of being able to use socialbots to communicate with the company throughout his customer journey. Socialbots therefore provide a means for firms to offer an open channel of communication and transparency to customers, which in turn strengthens their relationship and builds customer loyalty.

The final theme emerging is that, as a result of the instant and continuous communication socialbots provide, the purchase stage of the customer journey becomes less significant. This is due to consumers receiving the instant information that they need to make a purchase decision, therefore accelerating the purchase stage and encouraging consumers to buy more frequently. Figure 2 demonstrates that because of the socialbot's answers produced in the purchase stage, the decision to buy the product or service is made quickly and impulsively. Kim reinforces this with her experiences:

Kim: It's [the socialbot has] probably taken time off of searching for questions or going shopping but in another sense that's probably just led me to spend more money.

Murray also mentions how socialbots can automate the purchase decision, hence reducing the purchase decision making time (see Table 2).

In this instance, socialbots are easy to use and provide obtainable information, which creates a positive emotional response, encouraging young adult customers to buy impulsively. As a result, socialbots alter the relationship between young adult consumers and businesses. Potential customers now ask more questions about products to gather information, which leads to further purchasing and impulse buying. Furthermore, the open communication channel, available continuously throughout the journey, increases trust, which shortens the purchase decision. The socialbot experience therefore provides an opportunity for firms to build a strong customer relationship and take control over the information gathering phase.

\section{Personalisation through data mining}

Personalisation through data mining refers to the final customer journey involving the socialbot as a touchpoint. The socialbot technology uses information from the customer's social media profile in order to deliver promotions and personalised responses. In other words, the journey refers to when data mining is used for promotion or personalisation, which results in the consumer purchasing a product or service (see Figure 3). An example from the data is Nick's experience, where the socialbot uses his location during the interaction:

Nick: I liked Just Eat on Facebook and then they sent me a quiz and it was like if you get the question right you win $20 \%$ off...you can click things on the bot like inspire me and it will give you places near you. 
Nick's experience with Just Eat continues into the post-purchase stage, where he is constantly receiving notifications.:

Nick: The just eat one always nudges you like reminding you that just eat is there and reminding you to get a take away.

\section{[INSERT FIGURE 3]}

Personalisation through data mining may be beneficial to firms but it is also important to identify whether value is created for customers. For instance, the majority of the participants state that socialbots greet them by name, with the aim of establishing a relationship. The first theme within the journey is therefore how personalisation can humanise a business. In table 2 , Laura mentions that socialbots try and act as a friend whilst Jack articulates the importance of conversation:

Jack: I always think if you have a bit of banter with someone on the phone it makes it more enjoyable rather than it being boring. So I guess it was kind of the same thing when you are chatting with a socialbot, it's better when you have a bit more conversation.

Nevertheless, not all participants agree that the tailored approach is a major influencing factor and tend to see through the insincere personalisation strategy, which is the next theme identified from personalisation through data mining. Alex states very clearly that he is not impacted by the socialbot experience:

Alex: I know when they are trying to sell you things. They use your name because it's supposed to establish a connection with you and stuff but for me I'm not really that bothered.

As participants agree that the principal benefit of socialbots is having quick responses to their questions or problems, they concur that if exchanges are filled with social interaction this may take up unnecessary time. For example, some companies include jokes or emojis in the conversation, however, several participants expressed their dislike of socialbots showing this emotional intelligence. Adam felt that businesses using emojis made him feel uncomfortable:

Adam: Just when companies use emoji's and businesses use emoji's I think I just cringe.

Chloe and Kim (see Table 2) share the discomfort they feel about robots trying to be humans by stating that they can be "creepy":

Chloe: It's always a bit creepy to talk to robots I think.

Furthermore Figure 3 identifies that too much interaction between the socialbot and the customer, can have a negative impact on the overall impression of the brand. In this example, the socialbot continues to send promotions to the user, which are perceived to be irritating. In other words, a socialbot as an ATP can provide value but it needs to be utilised by the firm in a way that corresponds with customer motivations and expectations. Providing a customer service, knowledge service, fun quizzes, interactive promotions and personal touches seem 
to be well received by the young adult consumers. However, when the customer is not in control of these interactions, such as receiving continuous promotion notifications, the positive effect of the socialbot may be lost and the interactions can negatively impact the perception of the brand.

\section{Contributions and future direction}

The findings indicate that when brands use socialbots to interact with young adult consumers, this automated touchpoint (ATP) can influence the value equity and relationship equity drivers of customer equity. Firms place a considerable amount of attention on interacting with their customers due to the impact that this has on the retention of customer equity (Debnath et al., 2016). Furthermore, having a good customer relationship generally enhances the duration of the profitable affiliation and helps in building long lasting relationships (Alamgir and Uddin, 2017). By providing an alternative channel of communication through SNS, socialbots have changed how consumers converse with firms; young adults are now encouraged to interact more frequently and are no longer passive in their journey with the firm. Instead, this segment decide themselves when to engage through a highly accessible and often preferred channel of communication.

This paper therefore proposes that socialbots, as an ATP along the customer journey, can influence customer equity. For example, socialbots influence the value that consumers place on the firm. Firstly, the optimised complaint management experience indicates that quick responses and availability of socialbots on SNS provide young adults with a convenient channel of communication, which they value for customer services (Kaczorowska-Spychalska 2018). Convenience is a sub-category of value equity, within the customer equity framework (Lemon et al., 2001) and therefore the convenience of socialbots could enhance the overall customer equity. Secondly, socialbots encourage perceptions that the firm is innovative and investing in new technologies, which can also improve value equity (Lemon et al., 2001) and brand trust (Grayson et al., 2008).

Furthermore, as socialbots provide a channel of communication, which is continuous throughout the customer journey and offer young adults the confidence to communicate more frequently with the firm; this allows the firm to rectify any problems and alter negative emotions (Ou and Verhoef, 2017). Relationship equity is therefore enhanced by young adult customers communicating more frequently due to the preference of using a socialbot over email and phone-based customer services. It is also maintained by the continuous presence of the socialbot throughout the customer journey, as indicated in company controlled information sharing and personalisation through data mining. Consequently, there is scope for future studies to focus on ATPs within customer journeys and how these touchpoints impact the drivers of outcome measures such as customer equity. Lemon and Verhoef (2016) call for further research linking the customer experience with outcome measures. This study has therefore provided a qualitative basis of how socialbots interact with the customer experience but further quantitative research is required to test the impact that ATPs have on customer equity. 
Lemon and Verhoef (2016) also note that when touchpoints are technology based, there are blurred lines between brand-owned and partner-owned touchpoints. It is therefore important to introduce ATPs as a separate touchpoint along the customer journey, to decipher how they interact with brand-owned, partner-owned, customer-owned and social/external touchpoints. For instance, this research discovered that participants would be more likely to use socialbots if they had had previous negative experience of sending emails to firms and speaking to customer services. Socialbots, however, only achieve optimum success as an ATP if they are available alongside the more traditional methods of communication. The research demonstrates that participants use socialbots for less important issues but when the problem reaches critical mass or is too complex for a bot, speaking to a human becomes the preferred touchpoint, which is in correspondence with the work of Cerf (2015). This paper therefore introduces the socialbot as an alternative touchpoint and proposes that the ATP should be included within future customer journey frameworks to account for the differences of Al and automated technology to other more traditional touchpoints. Further research should investigate other Al as ATPs, which would enhance customer experience research within the digital, technology driven society.

The socialbot as an ATP has a significant impact on the young adult customer journey, which could enhance customer equity, but it is still unclear whether this new technology has a long lasting positive effect on the customer's experience. The data reveals negative emotions, especially relating to personalisation through data mining, such as annoyance with continuous notifications post-purchase, creepiness of the socialbot during purchase (Ostrom et al., 2019) and a reduction in the free will of the customer's information searching in the pre-purchase phase. Consequently, there is scope for future research to explore the dark side of socialbots to see if there is a long term negative effect on the consumer. Mick and Fournier's (1998) technology paradox theory could provide a valuable framework in which to evaluate the potential detrimental impact of the technology. They identify eight paradoxes relating to technology use (e.g. freedom/enslavement) and the impact of experiencing these paradoxes on conflict, anxiety and developing coping strategies. In this instance, young adults may develop a dependency on the socialbot for online purchases, which provides both freedom to purchase anything at any time but also a reliance on SNS and the socialbot, which could be classed as enslavement (Mick and Fournier, 1998).

\section{Managerial implications and limitations}

This study has produced several meaningful implications at the management level. The investigation has provided interesting insights into how valuable socialbots are as a customer service to firms targeting the young adult segment. For instance, the instant nature of the communication encourages customers to use the technology and the fact it was not a humanto-human interaction increases confidence. As such, customers are more likely to converse with the firm within their regular SNS setting (Stephen, 2017), which allows problems to be rectified easily. These problems are generally minor questions or issues and therefore using a socialbot to manage these queries is an inexpensive customer service strategy for firms to adopt. 
Socialbots are predominantly used for customer services during the post-purchase phase, however, this study reveals socialbots are also used for information gathering and promotion during the pre-purchase and purchase phases. Customer journies of company controlled information sharing and personalisation through data mining identify how firms can use socialbots to effectively increase impulse purchasing and reduce decision making time (Habib and Qayyum, 2018). Brands influence the consumers' decision making by providing programmed recommendations, which help control the information searching stage. Moreover, customer data is used to personalise the service and deliver promotions to the user, which is beneficial at first, however, too much promotion is detrimental to the customer's intention to repurchase. This suggests that brands using socialbots beyond customer services need to be aware that too much personalisation and promotion through data mining can negatively impact the customer's brand loyalty.

Although this research adds to the limited knowledge on socialbots as a customer service, the study is subject to limitations. Socialbot users participating in this study have been deliberately selected based on certain characteristics (e.g. age, socialbot experience), and are therefore not representative of the population. The selective nature of the study does not include individuals of different age groups and those who are not present on social media. Furthermore, the research focuses on the socialbot used on Facebook messenger and should therefore be extended to include socialbots on other platforms and chatbots present on company websites.

\section{References}

Alamgir, M. and Uddin, M.N. (2017), "The Role of Customer Relationship Management and Relationship Maintenance on Customer Retention- an Exploratory Study", Journal of Services Research, Vol. 17 No. 2, pp. 72-86.

Anderl, E., Becker, I., Von Wangenheim, F. and Schumann, J.H. (2016), “Mapping the customer journey: Lessons learned from graph-based online attribution modeling", International Journal of Research in Marketing, Vol. 33 No. 3, pp. 457-474.

Arnold, A. (2018) "Are we Entering the Era of Social Shopping?", available at: https://www.forbes.com/sites/andrewarnold/2018/04/04/are-we-entering-the-era-ofsocial-shopping/\#7944076356e1 (Accessed: $4^{\text {th }}$ April 2019).

Banyte, J., Gadeikiene, A., Rutelione, A. and Kakneviciene, I. (2016), "Expression of Personalization while Developing Long-Term Relationships with Service Customers", Engineering Economics, Vol. 27 No. 4, pp. 462-471.

Batra, R. and Keller, K. (2016), "Integrating Marketing Communications: New Findings, New Lessons, and New Ideas", Journal of Marketing, Vol. 80 No. 6, pp. 122-139.

Baxendale, S., Macdonald, E.K. and Wilson, H.N. (2015), "The impact of different touchpoints on brand consideration", Journal of Retailing, Vol. 91 No. 2, pp. 235-253.

Berry, L.L. (1995), "Relationship marketing of services-growing interest, emerging perspectives", Journal of the Academy of marketing science, Vol. 23 No. 4, pp. 236-245. 
Bitner, M.J. (1990), "Evaluating service encounters: the effects of physical surroundings and employee responses", Journal of Marketing, Vol. 54 No. 2, pp. 69-82.

Bitner, M.J. (1992), "Servicescapes: the impact of physical surroundings on customers and employees", Journal of Marketing, Vol. 56 No. 2, pp. 57-71.

Bitner, M.J., Ostrom, A.L. and Morgan, F.N. (2008), "Service blueprinting: a practical technique for service innovation", California management review, Vol. 50 No. 3, pp. 66-94.

Bleier, A., Harmeling, C.M. and Palmatier, R.W. (2019), "Creating Effective Online Customer Experiences", Journal of Marketing, Vol. 83 No. 2, pp. 98-119.

Blut, M., Wang, C. and Schoefer, K. (2016), "Factors influencing the acceptance of self-service technologies: A meta-analysis", Journal of Service Research, Vol. 19 No. 4, pp. 396-416.

Bolton, R.N. (1998), "A dynamic model of the duration of the customer's relationship with a continuous service provider: The role of satisfaction", Marketing science, Vol. 17 No. 1, pp. 45-65.

Bolton, R. N., McColl-Kennedy, J., Cheung, L., Gallan, A., Orsingher, C., Witell, L. and Zaki, M. (2018), "Customer experience challenges: bringing together digital, physical and social realms", Journal of Service Management, Vol. 29 No. 5, pp. 776-808.

Brandtzaeg P.B. and Følstad A. (2017), "Why People Use Chatbots", Internet Science, Vol. 10673 No. 1, pp. 377-392.

Braun, V. and Clarke, V. (2006), "Using thematic analysis in psychology", Qualitative research in psychology, Vol. 3 No. 2, pp. 77-101.

Brodie, R.J., Hollebeek, L.D., Jurić, B. and Ilić, A. (2011), “Customer engagement: Conceptual domain, fundamental propositions, and implications for research", Journal of service research, Vol. 14 No. 3, pp. 252-271.

Brynjolfsson, E., Hu, Y.J. and Rahman, M.S. (2013), "Competing in the Age of Omnichannel Retailing", MIT Sloan Management Review, Vol. 54 No. 4, p. 23.

Cerf, V.G. (2015), "The Human Touch", Communications of the ACM, Vol. 58 No. 4, pp. 7-7.

Daskou, S. and Mangina, E. E. (2003), "Artificial Intelligence in Managing Market Relationships: The Use of Intelligence Agents", Journal of Relationship Marketing, Vol. 2 No. 1, pp. 85-102.

Debnath, R., Datta, B. and Mukhopadhyay, S. (2016), "Customer Relationship Management Theory and Research in the New Millennium: Directions for Future Research", Journal of Relationship Marketing, Vol. 15 No. 4, pp. 299-325.

De Haan, E., Wiesel, T. and Pauwels, K. (2016), "The effectiveness of different forms of online advertising for purchase conversion in a multiple-channel attribution framework", International Journal of Research in Marketing, Vol. 33 No. 3, pp. 491-507. 
De Keyser, A., Schepers, J. and Konuş, U. (2015), "Multichannel customer segmentation: Does the after-sales channel matter? A replication and extension", International Journal of Research in Marketing, Vol. 32 No. 4, pp. 453-456.

Donnelly, C. and Scaff, R. (2018), "Who are the millennial shoppers? And what do they really want?" Available at: https://www.accenture.com/gb-en/insight-outlook-who-are-millennialshoppers-what-do-they-really-want-retail (accessed 26th November 2019).

Ellison, N. B., Steinfield, C. and Lampe, C. (2007), "The benefits of Facebook "friends": Social capital and college students' use of online social network sites", Journal of ComputerMediated Communication, Vol. 12 No. 4, pp. 1143-1168.

Eriksson, P. and Kovalainen, A. (2016), Qualitative Methods in Business Research, $2^{\text {nd }}$ ed., Sage Publications Ltd, London.

Glaser, B.G. and Strauss, A.L. (1967), The discovery of grounded theory: Strategies for qualitative research, Aldire, Chicago.

Grand View Research (2019), "Size of the chatbot market worldwide, in 2016 and 2025 (in million U.S. dollars)", Available at: https://www.statista.com/statistics/656596/worldwidechatbot-market/. (Accessed $27^{\text {th }}$ March 2019.)

Grayson, K., Johnson, D. and Chen, D.R. (2008), "Is Firm Trust Essential in a Trusted Environment? How Trust in the Business Context Influences Customers", Journal of Marketing Research (JMR), Vol. 45 No. 2, pp. 241-256.

Gupta, S., Hanssens, D., Hardie, B., Kahn, W., Kumar, V., Lin, N., Ravishanker, N. and Sriram, S. (2006), "Modeling customer lifetime value", Journal of service research, Vol. 9 No. 2, pp. 139-155.

Habib, M. D. and Qayyum, A. (2018), "Cognitive Emotion Theory and Emotion-Action Tendency in Online Impulsive Buying Behavior", Journal of Management Sciences, Vol. 5 No. 1, pp. 86-99.

Halvorsrud, R., Kvale, K. and Følstad, A. (2016), "Improving service quality through customer journey analysis", Journal of service theory and practice, Vol. 26 No. 6, pp. 840-867.

Hamilton, R. and Price, L. L. (2019), “Consumer journeys: developing consumer-based strategy", Journal of the Academy of Marketing Science, Vol. 47 No. 2, pp. 187-191.

Han, S. and Yang, H. (2018), "Understanding adoption of intelligent personal assistants: A parasocial relationship perspective", Industrial Management \& Data Systems, Vol. 118 No. 3, pp. 618-636.

Hanna, R., Rohm, A. and Crittenden, V.L. (2011), “We're all connected: The power of the social media ecosystem", Business Horizons, Vol. 54 No. 3, pp. 265-273.

Hildebrand, C. and Schlager, T. (2019), "Focusing on others before you shop: exposure to Facebook promotes conventional product configurations", Journal of the Academy of Marketing Science, Vol. 47 No. 2, pp. 291-307. 
Ho, A., Hancock, J. and Miner, A. (2018), "Psychological, Relational and Emotional Effects of Self-Disclosure After Conversations with a Chatbot", Journal of Communication, Vol. 68 No. 4, pp. $712-733$.

Ho, A. and Ito, K. (2019), "Consumption-oriented engagement in social network sites: Undesirable influence on personal well-being", European Journal of Marketing, Vol. 53 No. 7, pp. $1355-1377$

Jackins, T. (2016), "What is Natural Language Processing and How Does It Work?" Available at: https://blog.neospeech.com/what-is-natural-language-processing/ (Accessed $27^{\text {th }}$ March 2019).

Jüttner, U., Schaffner, D., Windler, K. and Maklan, S. (2013), "Customer service experiences: Developing and applying a sequentialincident laddering technique", European Journal of Marketing, Vol. 47 No. 5/6, pp. 738-769.

Kaczorowska-Spychalska, D. (2018), "Digital Technologies in the Process of Virtualization of Consumer Behaviour - Awareness of New Technologies", Management, Vol. 22 No. 2, pp. 187-203.

Kent, R. (1999), Marketing Research: Measurement, Method and Application, $1^{\text {st }}$ ed., International Thomson Business, London.

Kietzmann, J., Paschen, J. and Treen, E. (2018), “How Marketers Can Leverage Artificial Intelligence Along the Consumer Journey", Journal of Advertising Research, Vol. 1 No. 1, pp. 263-267.

Komidar, L., Zupancic, M., Socan, G. and Puklek Levpušcek, M. (2014), “Development and Construct Validation of the Individuation Test for Emerging Adults (ITEA)", Journal of Personality Assessment, Vol. 96 No. 5, pp. 503-514.

Konuş, U., Verhoef, P.C. and Neslin, S.A. (2008), "Multichannel shopper segments and their covariates", Journal of Retailing, Vol. 84 No. 4, pp. 398-413.

Krishnaswami, O. and Satyaprasad, B. (2010), Business Research Methods, $1^{\text {st }}$ ed., Himalaya Publishing House, Mumbai.

Kumar, V. and Reinartz, W. (2016), "Creating enduring customer value", Journal of Marketing, Vol. 80 No. 6, pp. 36-68.

Kumar, V. and Shah, D. (2009), "Expanding the role of marketing: from customer equity to market capitalization", Journal of Marketing, Vol. 73 No. 6, pp. 119-136.

Lajante, M. (2019) “Augmented Empathic Capacity: An Integrative Framework for Supporting Customer Engagement Throughout the Automated Customer Journey" In International Conference on Advances in National Brand and Private Label Marketing, Springer, Cham, pp. 121-129. 
Larivière, B., Bowen, D., Andreassen, T.W., Kunz, W., Sirianni, N.J., Voss, C., Wünderlich, N.V. and De Keyser, A. (2017), "'Service Encounter 2.0": An investigation into the roles of technology, employees and customers", Journal of Business Research, Vol. 79, pp. 238-246.

Leeflang, P.S., Spring, P.N., Van Doorn, J. and Wansbeek, T. (2013), "Identifying the direct mail-prone consumer", Journal of Global Scholars of Marketing Science, Vol. 23 No. 2, pp. 175-195.

Lemon, K.N., Rust, R.T. and Zeithaml, V.A. (2001), "What drives customer equity?”, Marketing management, Vol. 10 No. 1, pp. 20-25.

Lemon, K. and Verhoef, P. (2016), "Understanding Customer Experience Throughout the Customer Journey", Journal of Marketing, Vol. 80 No. 6, pp. 69-96.

Li, H. and Kannan, P.K. (2014), "Attributing conversions in a multichannel online marketing environment: An empirical model and a field experiment", Journal of Marketing Research, Vol. 51 No. 1, pp. 40-56.

Mariampolski, H. (2001), Qualitative Market Research, $1^{\text {st }}$ ed., SAGE Publications Inc., Thousand Oaks, California.

McCartan-Quinn, D., Durkin, M. and O'Donnell, A. (2004) "Exploring the application of IVR: lessons from retail banking”, The Service Industries Journal, Vol. 24 No. 3, pp. 150-168.

Meuter, M.L., Bitner, M.J., Ostrom, A.L. and Brown, S.W. (2005), "Choosing among alternative service delivery modes: An investigation of customer trial of self-service technologies", Journal of marketing, Vol. 69 No. 2, pp. 61-83.

Mick, D.G. and Fournier, S. (1998), "Paradoxes of technology: Consumer cognizance, emotions, and coping strategies", Journal of Consumer Research, Vol. 25 No. 2, pp. 123-143.

Moore, M. (2012), "Interactive media usage among millennial consumers", Journal of Consumer Marketing, Vol. 29 No. 6, pp. 436-444.

Neururer, M., Schlogl, S., Brinkschulte, L. and Groth, A. (2018), "Perceptions on Authenticity in Chat Bots", Multimodal Technologies and Interaction, Vol. 2 No. 3, pp. 60-79.

Ngai, E.W. (2005), “Customer relationship management research (1992-2002) An academic literature review and classification", Marketing intelligence \& planning, Vol. 23 No. 6, pp. 582605.

Novak, T. P. and Hoffman, D. L. (2019), "Relationship journeys in the internet of things: a new framework for understanding interactions between consumers and smart objects", Journal of the Academy of Marketing Science, Vol. 47 No. 2, pp. 216-237.

O'Gorman, D. \& Maclntosh, R. (2014), Research Methods for Business and Management: A Guide to Writing Your Dissertation, $1^{\text {st }}$ ed., Goodfellow Publishers Limited, Oxford. 
Ostrom, A.L., Fotheringham, D. and Bitner, M.J. (2019), "Customer Acceptance of Al in Service Encounters: Understanding Antecedents and Consequences" in Handbook of Service Science, Volume II, Springer, Cham, pp. 77-103.

Ou, Y.C. and Verhoef, P.C. (2017), "The impact of positive and negative emotions on loyalty intentions and their interactions with customer equity drivers", Journal of Business Research, Vol. 80, pp. 106-115.

Ou, Y.C., Verhoef, P.C. and Wiesel, T. (2017), "The effects of customer equity drivers on loyalty across services industries and firms", Journal of the Academy of Marketing Science, Vol. 45 No. 3, pp. 336-356.

Parasuraman, A., Zeithaml, V.A. and Berry, L.L. (1988), "SERVQUAL: A Multiple-Item Scale for Measuring Customer Cognizances of Service Quality", Journal of Retailing, Vol. 64 No. 1, pp. $12-40$.

Pate, S. and Adams, M. (2013), "The Influence of Social Networking Sites on Buying Behaviors of Millennials", Atlantic Marketing Journal, Vol. 2 No. 1, pp. 92-109.

Pozza, I., Heitz-Spahn, S. and Texier, L. (2017), "Generation Y multichannel behaviour for complex services: the need for human contact embodied through a distance relationship", Journal of Strategic Marketing, Vol. 25 No. 3, pp. 226-239.

Puccinelli, N. M., Goodstein, R. C., Grewal, D., Price, R., Raghubir, P. and Stewart, D. (2009), "Customer Experience Management in Retailing: Understanding the Buying Process", Journal of Retailing, Vol. 85 No. 1, pp. 15-30.

Rapp, A. (2015), “A qualitative investigation of gamification: Motivational factors in online gamified services and applications", in Gamification: Concepts, Methodologies, Tools, and Applications, IGI Global, pp. 32-48.

Reddy, T. (2017), "How chatbots can help reduce customer service costs by $30 \%$ ", Available at: https://www.ibm.com/blogs/watson/2017/10/how-chatbots-reduce-customer-servicecosts-by-30-percent/ (Accessed: $27^{\text {th }}$ March 2019).

Rouse, M. (2013), "Definition of Socialbot," Available at: https://whatis.techtarget.com/definition/socialbot (Accessed: $27^{\text {th }}$ March 2019).

Rubin, H. J. and Rubin, I. S. (2005), Qualitative interviewing; the art of hearing data, $2^{\text {nd }}$ ed., SAGE Publications Inc., Thousand Oaks, California.

Rust, R.T., Lemon, K.N. and Zeithaml, V.A. (2004), "Return on marketing: Using customer equity to focus marketing strategy", Journal of marketing, Vol. 68 No. 1, pp. 109-127.

Sheth, J.N. and Parvatiyar, A. (1995), "The evolution of relationship marketing", International business review, Vol. 4 No. 4, pp. 397-418.

Shostack, G.L. (1987), "Service positioning through structural change", Journal of marketing, Vol. 51 No. 1, pp. 34-43. 
Singh, A. and Hess, T. (2017), "How Chief Digital Officers Promote the Digital Transformation of their Companies", MIS Quarterly Executive, Vol. 16 No. 1, pp. 1-17.

Sprout Social (2018), "The Complete Guide to Chatbots in 2018", Available at: https://sproutsocial.com/insights/topics/chatbots/\#Facebook-Chatbots (Accessed: $\quad 1^{\text {st }}$ November 2018).

Stein, A. and Ramaseshan, B. (2016), "Towards the Identification of Customer Experience Touchpoint Elements", Journal of Retailing and Consumer Services, Vol. 30 No. 1, pp. 8-19.

Stephen, A.T. (2017), "Here Comes the Hyper-Connected Augmented Consumer", Marketing Intelligence Review, Vol. 9 No. 2, pp. 11-17.

Tax, S.S., McCutcheon, D. and Wilkinson, I.F. (2013), "The service delivery network (SDN) a customer-centric perspective of the customer journey", Journal of Service Research, Vol. 16 No. 4, pp. 454-470.

Teixeira, J., Patrício, L., Nunes, N.J., Nóbrega, L., Fisk, R.P. and Constantine, L. (2012), "Customer experience modeling: from customer experience to service design", Journal of Service management, Vol. 23 No. 3, pp. 362-376.

Utz, S. (2016), "Is LinkedIn making you more successful? The informational benefits derived from public social media", New Media and Society, Vol. 18 No. 11, pp. 2685-2702

Varnali, K. (2019), "Understanding customer journey from the lenses of complexity theory", The Service Industries Journal, Vol. 39 No. 11/12, pp. 820-835.

Verhoef, P.C., Neslin, S.A. and Vroomen, B. (2007), "Multichannel customer management: Understanding the research-shopper phenomenon", International journal of research in marketing, Vol. 24 No. 2, pp. 129-148.

Vogel, V., Evanschitzky, H. and Ramaseshan, B. (2008), "Customer equity drivers and future sales", Journal of marketing, Vol. 72 No. 6, pp. 98-108.

Voorhees, C.M., Fombelle, P.W., Gregoire, Y., Bone, S., Gustafsson, A., Sousa, R. and Walkowiak, T. (2017), "Service encounters, experiences and the customer journey: Defining the field and a call to expand our lens", Journal of Business Research, Vol. 79, pp. 269-280.

Wang, R.J.H., Malthouse, E.C. and Krishnamurthi, L. (2015), “On the go: How mobile shopping affects customer purchase behavior", Journal of Retailing, Vol. 91 No. 2, pp. 217-234.

Wolny, J. and Charoensuksai, N. J. (2014), "Mapping Customer Journeys in Multichannel Decision-Making", Journal of Direct, Data and Digital Marketing Practices, Vol. 15 No. 4, pp. 317-326.

Xu, L., Duan, J.A. and Whinston, A. (2014), "Path to purchase: A mutually exciting point process model for online advertising and conversion", Management Science, Vol. 60 No. 6, pp. 1392-1412.

Xu, A., Liu, Z., Guo, Y., Sinha, V. and Akkiraju, R. (2017), “A New Chatbot for Customer Service on Social Media", IBM Research, Vol. 1 No. 1, pp. 3506-3510. 
Zarouali, B., Broeck, E., Walrave, M. and Poels, K. (2018), “Predicting Consumer Responses to a Chatbot on Facebook", Cyber psychology, Behavior, and Social Networking, Vol. 21 No. 8, pp. 491-497.

Zeithaml, V.A., Lemon, K.N. and Rust, R.T. (2001), Driving customer equity: How customer lifetime value is reshaping corporate strategy, Simon and Schuster, New York, NY. 


\begin{tabular}{|l|l|l|l|}
\hline Name* & Gender & Age & User Type \\
\hline Angela & Female & 20 & Weekly \\
\hline Laura & Female & 22 & Daily \\
\hline Chloe & Female & 24 & Monthly \\
\hline Nick & Male & 22 & Monthly \\
\hline Adam & Male & 21 & Daily \\
\hline Kathryn & Female & 21 & Monthly \\
\hline Frank & Male & 22 & Weekly \\
\hline Tessa & Female & 21 & Daily \\
\hline Rory & Male & 21 & Monthly \\
\hline Murray & Male & 26 & Weekly \\
\hline Jack & Male & 21 & Monthly \\
\hline Alex & Male & 23 & Weekly \\
\hline Molly & Female & 21 & Monthly \\
\hline Nicola & Female & 25 & Weekly \\
\hline Kim & Female & 22 & Daily \\
\hline Rachel & Female & 19 & Monthly \\
\hline Bill & Male & 25 & Daily \\
\hline
\end{tabular}

* Pseudonym names created for the purpose of the research

Table 1: Participant information including socialbot frequency of use 


\begin{tabular}{|c|c|c|}
\hline $\begin{array}{l}\text { Customer } \\
\text { Journey }\end{array}$ & Coded Theme & Example Quotations \\
\hline \multirow{5}{*}{$\begin{array}{l}\text { Optimised } \\
\text { complaint } \\
\text { management }\end{array}$} & $\begin{array}{l}\text { Efficiency of socialbot } \\
\text { response }\end{array}$ & $\begin{array}{l}\text { Nicola: It's good that you can just message them } \\
\text { straight away and get a quick response back }\end{array}$ \\
\hline & $\begin{array}{l}\text { Convenience of socialbot } \\
\text { customer service }\end{array}$ & $\begin{array}{l}\text { Tessa: Obviously people use messenger all the time } \\
\text { anyway so it's good just to be able to go and speak } \\
\text { to Adidas or something if you've got an issue. It's } \\
\text { quite handy and I think it's a good idea for sure. } \\
\text { You know how many customers will probably have } \\
\text { a Facebook so it's smart. I think it's a smart move. }\end{array}$ \\
\hline & $\begin{array}{l}\text { Interaction with other } \\
\text { touchpoints }\end{array}$ & $\begin{array}{l}\text { Tessa: I hate like wasting time so and I just hate } \\
\text { email. Emails are good but you don't know when } \\
\text { they have read it or when they are going to reply } \\
\text { whereas on those [socialbots] they are just really } \\
\text { instant I just prefer them. } \\
\text { Kathryn: I would always prefer to phone someone } \\
\text { up or have another person on the end but if it was } \\
\text { quicker just to get a quick answer from a bot then I } \\
\text { would just do that over a person. }\end{array}$ \\
\hline & $\begin{array}{l}\text { Changing relationships } \\
\text { between customers and } \\
\text { the firm }\end{array}$ & $\begin{array}{l}\text { Angela: I think it probably made me like them more } \\
\text { just because going back to ASOS, they just fixed it } \\
\text { so quickly and there was no need for any stress, } \\
\text { just got my money off. So it all worked out and it } \\
\text { made me like them better because it was quicker } \\
\text { and there was no stress involved. }\end{array}$ \\
\hline & $\begin{array}{l}\text { Importance of innovation } \\
\text { on brand perceptions }\end{array}$ & $\begin{array}{l}\text { Alex: It does kind of annoy me when I see a } \\
\text { company that doesn't have a bot, it just has a call } \\
\text { number, because I hate speaking to people, I much } \\
\text { prefer a socialbot. I would use it again. }\end{array}$ \\
\hline \multirow[t]{3}{*}{$\begin{array}{l}\text { Company } \\
\text { controlled } \\
\text { information } \\
\text { sharing }\end{array}$} & $\begin{array}{l}\text { Instant information } \\
\text { gathering from the } \\
\text { socialbot }\end{array}$ & $\begin{array}{l}\text { Frank: Yes, I think more and more it [using } \\
\text { socialbots] will be done, especially with this } \\
\text { information thing, it's a really really great way of } \\
\text { finding out what you want exactly and what } \\
\text { product better serves your customer needs from } \\
\text { the customer sides. How you can meet your needs } \\
\text { through the product. I think it's a really good way } \\
\text { of doing that and I think it will do that better and } \\
\text { better in the future. }\end{array}$ \\
\hline & $\begin{array}{l}\text { Consistency of socialbot } \\
\text { throughout the customer } \\
\text { journey }\end{array}$ & $\begin{array}{l}\text { Rory: I think being able to communicate with the } \\
\text { company throughout the process of, of making a } \\
\text { purchasing decision and even after making the } \\
\text { purchase, is a very positive thing. }\end{array}$ \\
\hline & $\begin{array}{l}\text { Socialbots creating ease } \\
\text { of purchase }\end{array}$ & $\begin{array}{l}\text { Murray: I think it will completely encompass } \\
\text { everything that humans do and how they interact } \\
\text { with businesses. It's almost gonna get to the point } \\
\text { where I think we will think less about brands and } \\
\text { the business and more about saying get me this [a } \\
\text { product or service] and it's just gonna be so more } \\
\text { automatic. }\end{array}$ \\
\hline
\end{tabular}




\begin{tabular}{|l|l|l|}
\hline $\begin{array}{l}\text { Personalisation } \\
\text { through data } \\
\text { mining }\end{array}$ & $\begin{array}{l}\text { Socialbot personalisation } \\
\text { humanising the firm }\end{array}$ & $\begin{array}{l}\text { Laura: They always act like they're your friend in } \\
\text { some way and like you are just messaging your } \\
\text { friend asking about something. }\end{array}$ \\
\cline { 2 - 3 } & $\begin{array}{l}\text { Insincere socialbot } \\
\text { personalisation }\end{array}$ & $\begin{array}{l}\text { Kim: Machines aren't necessarily meant to have a } \\
\text { personality, so I think that would make me slightly } \\
\text { uncomfortable. }\end{array}$ \\
\hline
\end{tabular}

Table 2: Results of the thematic analysis 
Figure 1: Optimised complaint management

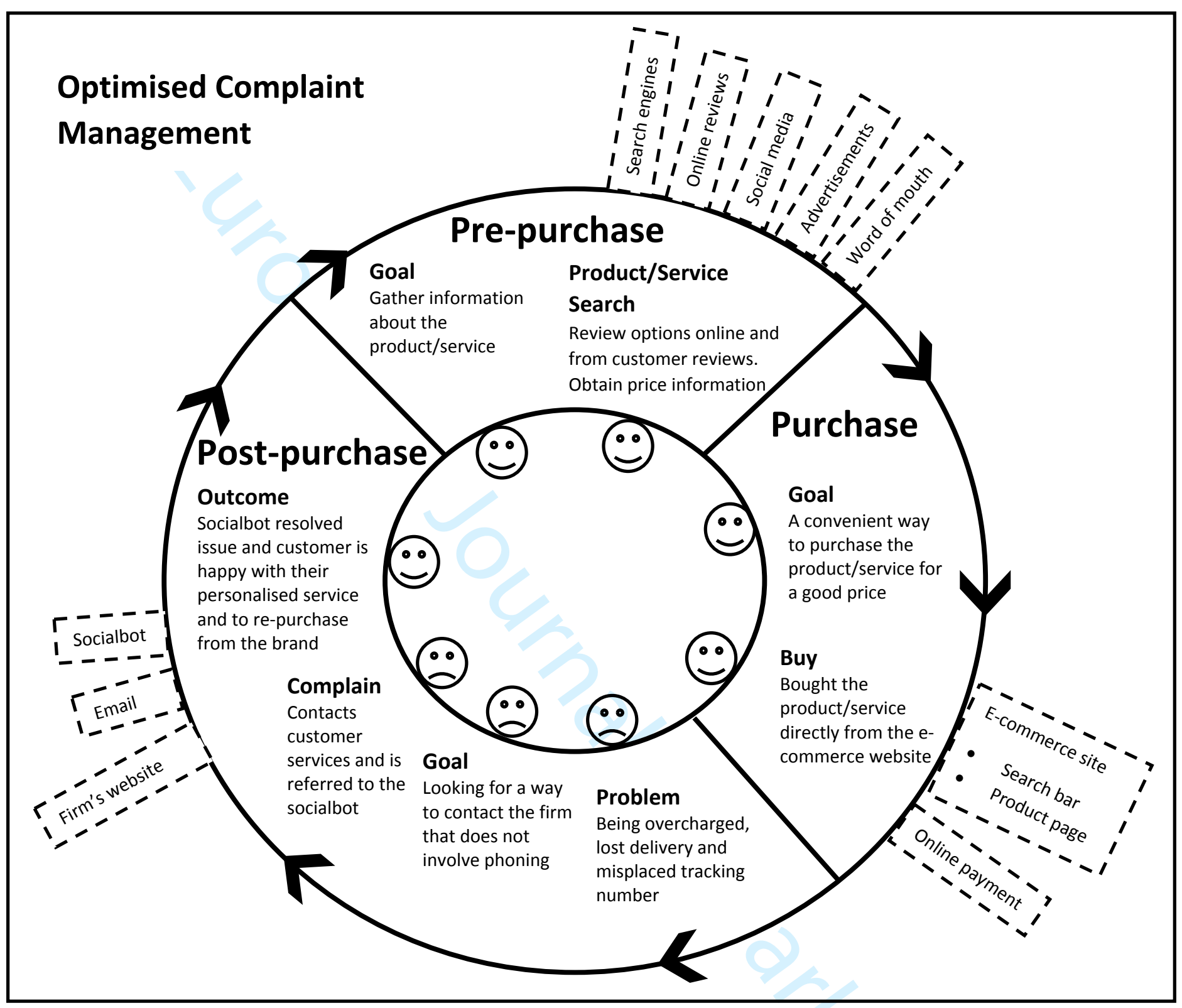


Figure 2: Company controlled information sharing

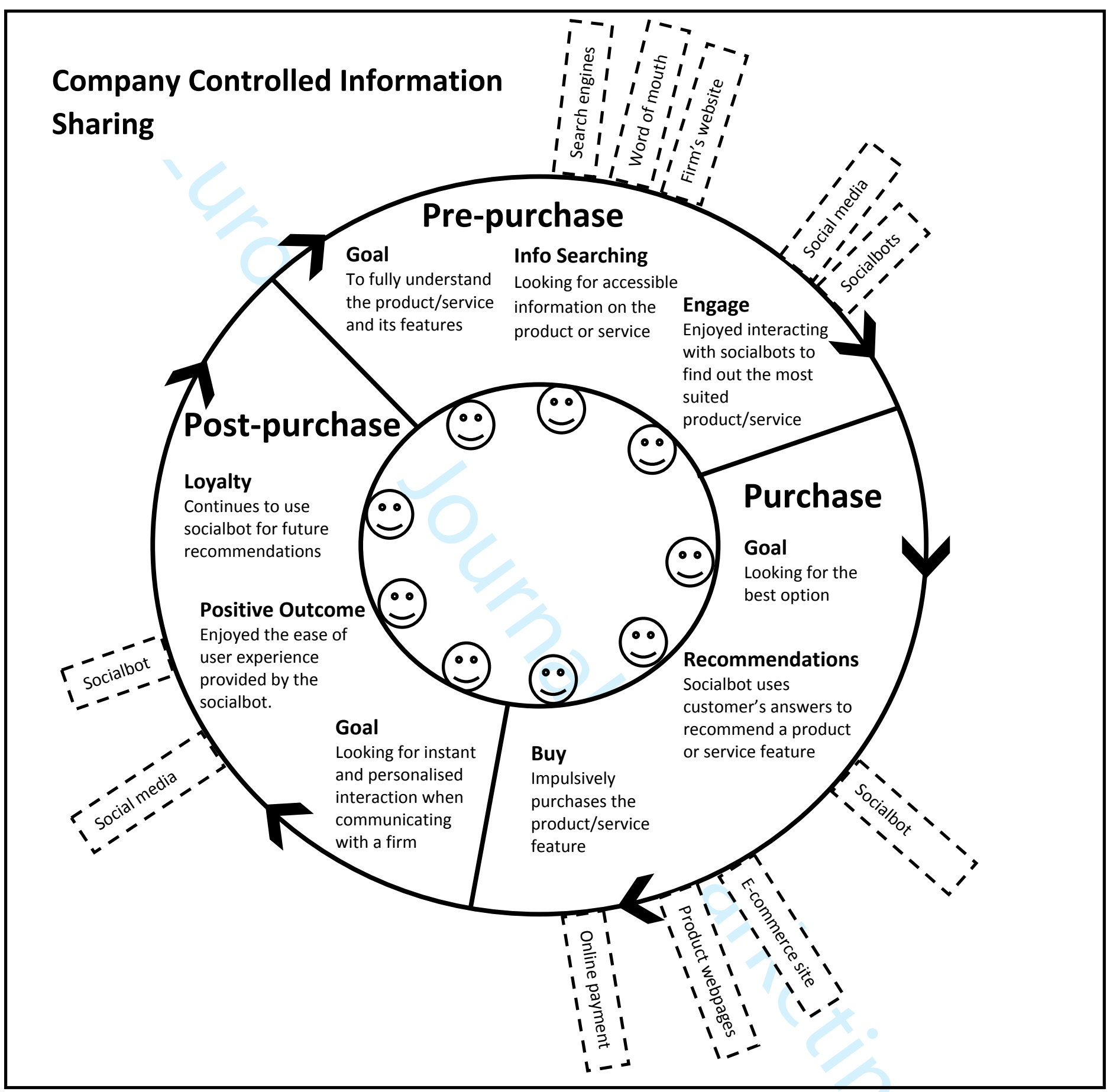


Figure 3: Personalisation through data mining

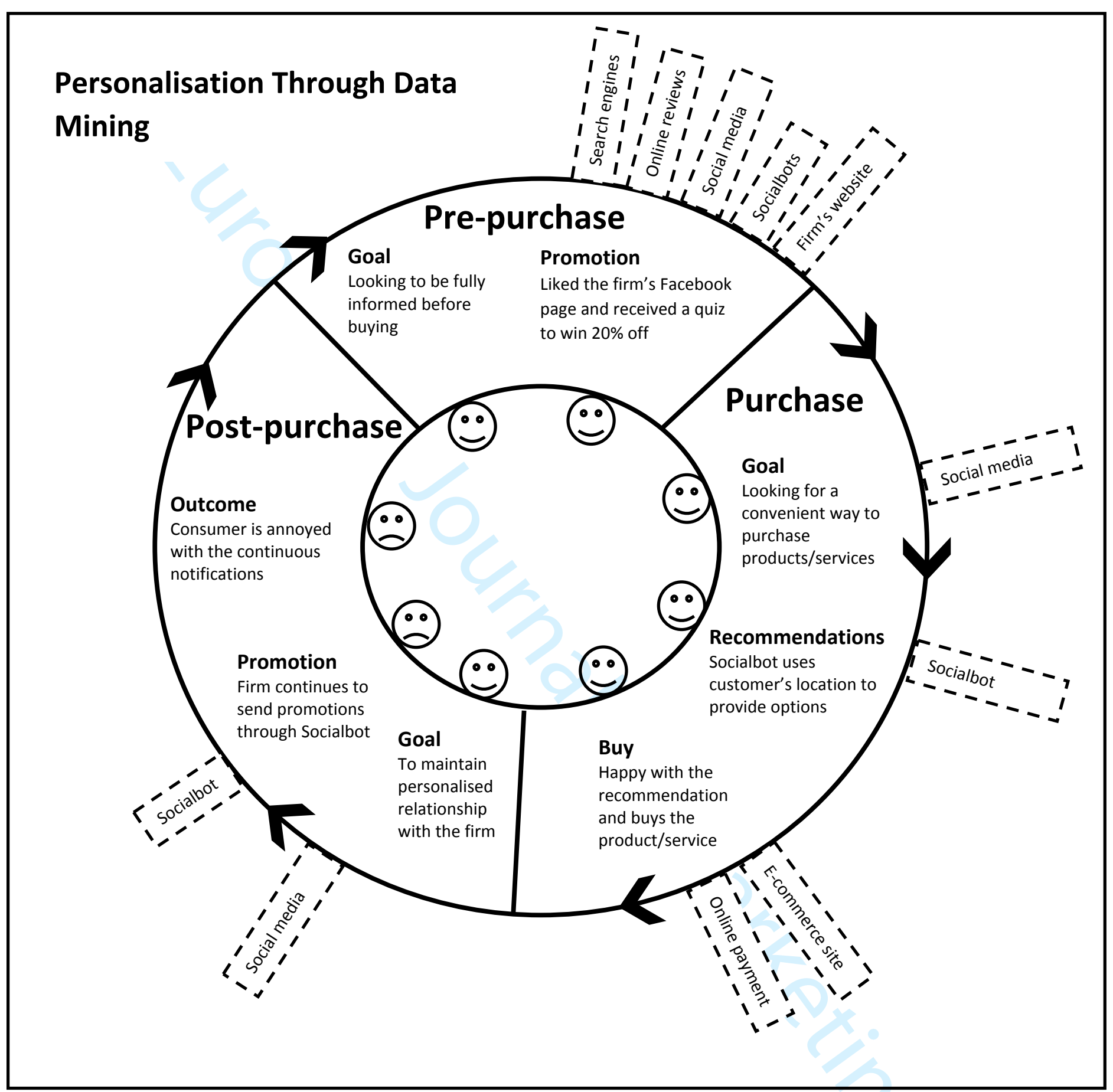


Reviewer(s)' Comments to Author:

Reviewer: 1

Recommendation: Minor Revision

\section{Comments:}

Thank you for the revision. I wish the authors had done a more detailed presentation of the revisions with each reviewer comment listed with a response. It was quite difficult to follow along with the generic letter and the new document. With that said I appreciate the work the authors have done to the paper. As mentioned above, I find the biggest issue are the three metaphors/ pop-culture names they have chosen for the findings/ themes. It is an unnecessary practice that may alienate some readers instead of using more descriptive names.

Thank you for appreciating the changes. I have now placed reviewer comments and my responses in one document at the end of the paper. Hopefully this will make the changes easier to follow. My apologies for not doing this before. I completely understand that the pop-culture references may alienate readers and so these have now been changed to reflect the nuances in the customer journey. The three names have been changes as follows:

- I,Robot has been changed to optimated complaint management

- Bandersnatch has been changed to company controlled information sharing

- Big Brother has been changed to personalisation through data mining

P. 2 line 461.250 million is 1.25 billion if you are referring to 1,25 million that is different. Please clarify.

Thank you for spotting this. The figure on P. 2 line 46 has now been changed to 1.25 billion.

P. 2 line 53 what do you mean with "shift from e-commerce to social shopping" Not clear.

P. 2 line 53, an example has now been provided in brackets, which provides more detail on what is meant by social shopping

P. 2. line 55 With present absences in knowledge? Clarify.

P. 2. line 55, this has now been changed to 'There are few studies relating to the value that socialbots create for the consumer' to provide more context behind absences in knowledge.

P. 4 line 19 sensorial do you mean sensory?

P. 4 line 19. Yes it was meant to say sensory. Thank you for spotting this, it has now been changed.

P. 6 line 27 Socialbots are relatively new tools.

P. 6 line 27 has been changed to the suggestion by the reviewer-thank you for the suggestion

P. 12 quote by Kathryn sounds contradictory.

The quote on P12, which was orginally by Kathyrn has now been altered to a quote by Frank, which is less contradictory and highlights the point more. 


\section{P. 16 spell out ATP}

On page 16, at the beginning of the contributions section, ATP has spelled out to introduce the acronym for the remainder of the section

Additional Questions:

Do you want credit for reviewing this manuscript in Publons? [<a

href="https://publons.com/in/Emerald/" target="new">what's this?</a>]

By selecting "Yes" you are opting in to the Publons service and data about this review (including your name and the review itself) will be transferred to Publons. You may opt-out of this service at any time.: Yes

1. Originality: Does the paper contain new and significant information adequate to justify publication?: Yes.

2. Relationship to Literature: Does the paper demonstrate an adequate understanding of the relevant literature in the field and cite an appropriate range of literature sources? Is any significant work ignored?: It is adequate.

3. Methodology: Is the paper's argument built on an appropriate base of theory, concepts or other ideas? Has the research or equivalent intellectual work on which the paper is based been well designed? Are the methods employed appropriate?: More detail has been added.

4. Results: Are results presented clearly and analysed appropriately? Do the conclusions adequately tie together the other elements of the paper?: Yes. However, I think more descriptive themes instead of the pop culture references may be better understood by readers. For instance Big Brother could be referred to as Privacy and surveillance.

Thank you for your comments, the themes have now been changes to be more descriptive. You can see these changes from page 9 and throughout the remainder of the document. These are how the themes have been altered:

\section{- I,Robot has been changed to optimated complaint management \\ - Bandersnatch has been changed to company controlled information sharing \\ - Big Brother has been changed to personalisation through data mining}

5. Practicality and/or Research implications: Does the paper identify clearly any implications for practice and/or further research? Are these implications consistent with the findings and conclusions of the paper?: I struggle a bit with the pop-culture chosen themes chosen to present the findings and how this relates to practical implications. I think the authors can do a better job at fleshing this out.

The altered themes are more descriptive, they have therefore been fleshed out, which straight away makes the themes more relatable to the practical implications suggested on page 17-18. 
6. Quality of Communication: Does the paper clearly express its case, measured against the technical language of the fields and the expected knowledge of the journal's readership? Has attention been paid to the clarity of expression and readability, such as sentence structure, jargon use, acronyms, etc.: Some quotes reads a bit odd but I think that is due to the translation so I think looking at these again to make sure they make sense is needed (e.g., p. 12 line 3-6).

The quotes have been re-read and edited where necessary. The conflicting quote on p.12, has now been changed to a quote by Frank.

The manuscript needs proofreading for English languish.

The manuscript, tables and diagrams have been proofread for spelling and grammar errors and have been improved where necessary. 